\title{
Ulcerative colitis associated with aplastic anemia and extra intestinal manifestations: Case presentation
}

\author{
Maha M Maher ${ }^{1 *}$, Fatma Adel ${ }^{1}$ and Hazem M Rizk ${ }^{2}$ \\ ${ }^{1}$ Gastroenterology and Hepatology Unit, Masoura University, Specialized Medical Hospital, Egypt \\ ${ }^{2}$ London Northwest University Hospital NHS Trust, UK
}

\begin{abstract}
Association between inflammatory bowel disease (IBD) and myelodysplastic syndrome, in particular aplastic anaemia was reported with possible share a common immune dysfunction pathway. Extra intestinal manifestations of IBD are also common and usually related to the activity of IBD. We report a case of active ulcerative colitis associated with aplastic anaemia, dermatological and thromboembolic extra intestinal manifestations.
\end{abstract}

\section{Introduction}

Ulcerative colitis (UC) is an autoimmune disease that mainly affects the mucosa of the colon. Haematological affection is commonly associated with UC. It can be due to multiple causes: blood loss, malabsorption, chronicity of UC, sepsis, associated myelodysplastic syndromes, or hemolysis [1]. There is a clinical association between inflammatory bowel disease (IBD) and myelodysplastic syndrome, maybe they share an immune dysfunction and impairment of T-lymphocytes activities [2]. Extra intestinal manifestations of IBD are usually accompanied with activity of IBD.

\section{Case presentation}

We present a case of male patient 35 years old, complained of bloody diarrhoea more than 6 times / day. Patient has been diagnosed as ulcerative colitis for four years. On examination he was pale, average built, with slight diminution of vision. There was area of Pyoderma gangrenosum on extensor side of his right thigh. Patient had history of deep venous thrombosis for which he received warfarin for 6 months. His current therapy also included mesalamine 3 grams/day, $300 \mathrm{mg}$ hydrocortisone was started after his admission in Mansoura specialized medical hospital. Abdomen ultrasound and CT were free.

His laboratory testing showed: Complete Blood Count: haemoglobin was $9.2 \mathrm{gm} / \mathrm{dl}$, MCV: $77 \mathrm{fl}$, Platelets: 42 / $\mathrm{cmm}^{3}$, WBCs:3 / $\mathrm{cmm}^{3}$, Reticulocyte count:1.2\%, INR: 1 , ferritin: $11.5 \mathrm{ng} / \mathrm{ml}, \mathrm{LDH}: 265$ U/I (100-190), Creatinine: $0.9 \mathrm{mg} / \mathrm{dl}$, uric acid: 4.8, Urinalysis: NAD. Serum calcium ionized $0.83 \mathrm{mmol} / \mathrm{L}(1.15-1.32)$, Serum albumin: 3.8 g/dl, serum bilirubin : $0.8 \mathrm{mg} / \mathrm{dl}$ (direct) $0.2 \mathrm{mg} / \mathrm{dl}$, ALT: $13 \mathrm{mg} / \mathrm{dl}$, AST: $13 \mathrm{mg} / \mathrm{dl}$, alkaline phosphatase :228 U/L HBs-Ag, HBc -Ab IgM, HCV Ab, HIV Ab: all are -ve, CMV IgM -ve, Quantiferon TB:-ve. ESR: 30, CRP: 60, faecal calprotectin: $1000 \mathrm{ug} / \mathrm{g}$, Coomb's (direct) positive, (indirect) negative, ANA -ve, Prothrombin gene mutation: normal, Factor V Leiden: heterogenous gene mutation was detected.

CBC was repeated serially due to pancytopenia. Haematological consultation advised bone marrow biopsy that showed marked hypo cellular bone marrow with $5-10 \%$ cellularity, the erythroid series is represented by few megakaryocytes and reduced myeloid series, with no detected abnormal deposits; picture suggestive of aplastic anaemia. He was advised to start Eltrombopag daily and epoetin alpha weekly with frequent substitution by transfusion of packed RBCs and platelets. Anticoagulant was started by recombinant hirudin $15 \mathrm{mg} \mathrm{sc} / 12$ hours. There was problem related to stating azathioprine as immune modulator due to his pancytopenia yet, anti TNF infliximab was started after 2 weeks of his admission as well as cyclosporine by dose $300 \mathrm{mg}$ daily. $\mathrm{He}$ showed improvement concerning the pyoderma gangrenosum and the activity of ulcerative colitis (Table 1).

During his admission patient complained of more diminution of vision. Ophthalmological consultation ordered fluorescein angiography of the right eye that showed dilated capillaries of optic disc indicating disc edema and areas of haemorrhage giving impression of nonischemic central retinal vein occlusion with diffuse maculopathy. As for the left eye there was mild retinal haemorrhage (impending vein occlusion) with increased central macular thickness and neurosensory detachment. He was advised to have frequent laser photocoagulation sessions that showed slight improvement (Figure 1).

Table 1. Serial CBC

\begin{tabular}{|l|c|c|c|c|c|c|c|}
\hline & $\begin{array}{c}\text { Start of } \\
\text { ttt }\end{array}$ & $\begin{array}{c}\text { After 1 } \\
\text { week }\end{array}$ & 2 weeks & 3 weeks & 2 months & 3 months & 4 months \\
\hline Hb & 10.8 & 10.1 & 8.7 & 8.6 & 7.9 & 6.2 & 8.9 \\
\hline Mcv & 77 & 79 & 85 & 78 & 79 & 80 & 81 \\
\hline WBC & 2.4 & 2.1 & 4.9 & 5.3 & 1.9 & 2.3 & 1.8 \\
\hline Neutrophils & $23 \%$ & $26 \%$ & $20 \%$ & $20 \%$ & 20 & 20 & 7.5 \\
\hline Platelets & 26 & 29 & 26 & 38 & 13 & 21 & 16 \\
\hline
\end{tabular}

${ }^{\star}$ Correspondence to: Maha Mohammad Maher, Gastroenterology and Hepatology Unit, Masoura University, Specialized Medical Hospital, Egypt, Tel: 002136673398 52; E-mail: wahibaguenifi@yahoo.fr

Key words: aplastic anaemia, immune dysfunction pathway, inflammatory bowel disease

Received: May 07, 2020; Accepted: May 22, 2020; Published: May 25, 2020 


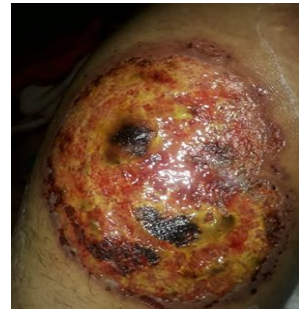

A) Pyoderma gangrenosum

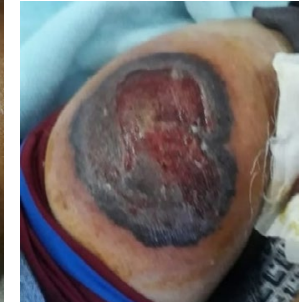

b) Healing pyoderma

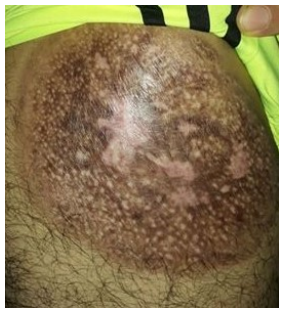

c) Healed lesion
Figure 1. Laser photocoagulation sessions

\section{Discussion and conclusion}

Ulcerative colitis (UC) is an inflammatory bowel disease of unknown etiology that mainly affects the mucosa of the colon due to immune reaction and immunogenetic factors. Haematological affection is commonly associated with UC. It can be due to multiple causes: blood loss, malabsorption, chronicity of UC, sepsis, associated myelodysplastic syndromes, or haemolysis [1]. Several investigators have suggested a clinical association between inflammatory bowel disease (IBD) and myelodysplastic syndrome, may be they share an immune dysfunction and impairment of T-lymphocytes activities, that contribute to peripheral blood pancytopenia and bone marrow hypoplasia [2-5].

Aplastic anaemia (AA) is a clinical syndrome with failure of bone marrow hematopoietic synthesis. The symptoms of AA include bone marrow hypoplasia, pancytopenia and anaemia, bleeding, and infection syndrome. The possible pathogenic elements of AA related to IBD case include drugs like mesalazine and sulfasalazine, chemicals, radiation, immune dysfunction, and hereditary reasons $[6,7]$. Mesalazine induced severe AA in patients with UC has also been reported after the treatment by 4 months [8]. In the presented case, the AA was diagnosed after UC by 4 years. When mesalamine treatment was stopped and started antiTNF the AA was still present.

Aplastic anaemia relation to IBD may be considered a matter of association rather than complication or extra intestinal manifestation making the treatment of such cases a big challenge. The association of AA is more common with $\mathrm{UC}$ than $\mathrm{CD}$, yet six cases of $\mathrm{CD}$ were reported associated with $\mathrm{AA}$ [9]. It was reported that in more than half of the cases there is a favourable response to treatment with immunosuppressants for patients with UC and AA due to the common immune pathogenesis [10]. Immunosuppressants as cyclosporine acts directly by suppressing lymphokine production by $\mathrm{T}$ cells and it shows a good response in a case of UC associated AA [11]. However, it does not show improvement in our case despite its use for about 6 months. This supports the idea of considering AA to be associated with UC rather than to be supposed as an extra intestinal manifestation of IBD. So the next step in the management of AA in our case may be bone marrow transplant (BMT) that may show success. This can be the same as it was reported in a case of AA that was associated with UC and failed cyclosporine treatment so BMT was done [12].

The ophthalmological manifestation in this case was in the form of central retinal vein occlusion. It can be mostly attributed to the hypercoagulable complication of the active UC. Thromboembolic events resulting from hypercoagulable state in patients with IBD can lead to pulmonary embolism. Thrombosis has been reported in $1.8 \%$ of patients with UC due to inflammation, fluid depletion, hospital immobilization, surgery, steroid therapy, and use of central venous catheters. Some proinflammatory cytokines have thrombogenic effect such as interleukin-6 [13-15]. Therefore, our patient continued anticoagulant therapy. Recombinant hirudin was used to avoid heparin induced thrombocytopenia.
Our case of UC was complicated with pyoderma gangrenosum, which highlights the dermatological complications of UC. Skin involvement has been described in $10 \%$ to $15 \%$ of patients with IBD [15]. Maybe either erythema nodosum or pyoderma gangrenosum. Lesions are found typically on the extensor surfaces of the extremities, and usually resolves with treatment of the underlying IBD [17] the same that happened in our case after starting the antiTNF.

This can be the only case mentioned in literature that combine the extra intestinal manifestation of UC in the form of pyoderma gangrenosum and thromboembolic manifestations together with the association of AA.

\section{References}

1. Sharman BC, Yachla SK, Mishra RN, Gupta D (1996) Hypoplastic anemia associated with ulcerative colitis in a child. J Pedia Gastroenterol Nutr 23: 326-328. [Crossref]

2. Eng C, Farraye FA, Shulman LN, Peppercorn MA, Krauss CM, et al. (1992) The association between the myelodysplastic syndromes and Crohn disease. Ann Intern Med 117: 661-662. [Crossref]

3. Harewood GC, Loftus EV Jr, Tefferi A, Tremaine WJ, Sandborn WJ (1999) Concurrent inflammatory bowel disease and myelodysplastic syndromes. Inflam Bowel Dis 5: 98103. [Crossref]

4. Sahay R, Prangnell DR, Scott BB (1993) Inflammatory bowel disease and refractory anemia (myelodysplasia). Gut 34: 1630-1631. [Crossref]

5. Hebbar M, Kozlowski D, Wattel S, Mastrini S, Dievart M, et al. (1997) Association between myelodysplastic syndromes and inflammatory bowel disease. Report of seven new cases and review of the literature. Leukemia 11: 2188-2191. [Crossref]

6. Laidlaw ST, Reilly JT (1994) Antilymphocite globulin for mesalazine-associated aplastic anaemia. Lancet 343: 981-982. [Crossref]

7. Takaku T, Calado RT, Kajigaya S, Young NS (2009) Interleukin-23 receptor (IL-23R) gene polymorphisms in acquired aplastic anemia. Annuals Hematol 88: 653-657. [Crossref]

8. Otsubo H, Kaito K, Sekita T, Shimada T, Kobayashi M, et al. (1998) Mesalazine-associated severe aplastic anemia successfully treated with antithymocyte globulin, cyclosporin and granulocyte colony-stimulating factor. Int J Hematol 68: 445-448. [Crossref]

9. Su S, Liu ZZ, Wang F, Zhang Y, Chu Y, et al. (2019) Aplastic anemia associated with Crohn's disease: a tertiary center retrospective study. Annuals Hematol 98: 2053-2061. [Crossref]

10. Kishikawa H, Nishida J, Nakano M, Hirano E, Morishita T, et al. (2003) Ulcerative colitis associated with aplastic anemia. Dig Dis Sci 48 :1376-1379.

11. Ghavidel A (2013) Ulcerative Colitis Associated with Aplastic Anemia. A Case Rep Middle East J Dig Dis 5: 230-234.

12. Shimada T, Maeda T, Ishikawa M, Okamura D, Ito Y, et al. (2012) Aplastic anemia complicated with ulcerative colitis. Rinsho Ketsueki 53: 224-228.

13. Gabay C, Kushner I (1999) Acute-phase proteins and other systemic responses to inflammation. N Engl J Med 340: 448-454. [Crossref]

14. McEver RP (2001) Adhesive interactions of leukocytes, platelets, and the vessel wall during hemostasis and inflammation. Thromb Haemost 86: 746-756. [Crossref]

15. Stouthard JM, Levi M, Hack CE, Veenhof CH, Romijn HA, et al. (1996) Interleukin-6 stimulates coagulation, not fibrinolysis, in humans. Thromb Haemost 76: 738-742. [Crossref]

16. Greenstein AJ, Janowitz HD, Sachar DB (1976) The extra-intestinal complications of Crohn's disease and ulcerative colitis: a study of 700 patients. Medicine (Baltimore) 55: 401-412. [Crossref]

17. Powell RJ, Holbrook MR, Stevens A (1997) Pyoderma gangrenosum and its treatment Lancet 350: 1720-1721.

Copyright: (C2020 Maher MM. This is an open-access article distributed under the terms of the Creative Commons Attribution License, which permits unrestricted use, distribution, and reproduction in any medium, provided the original author and source are credited. 